\title{
Response surface methodology for ozonation of trifluralin using advanced oxidation processes in an airlift photoreactor
}

\author{
J. Behin ${ }^{1} \cdot$ N. Farhadian ${ }^{1}$
}

Received: 13 March 2016/Accepted: 14 June 2016/Published online: 25 June 2016

(c) The Author(s) 2016. This article is published with open access at Springerlink.com

\begin{abstract}
Degradation of trifluralin, as a wide used pesticide, was investigated by advance oxidation process comprising $\mathrm{O}_{3} / \mathrm{UV} / \mathrm{H}_{2} \mathrm{O}_{2}$ in a concentric tube airlift photoreactor. Main and interactive effects of three independent factors including $\mathrm{pH}(5-9)$, superficial gas velocity $(0.05-0.15 \mathrm{~cm} / \mathrm{s})$ and time $(20-60 \mathrm{~min})$ on the removal efficiency were assessed using central composite facecentered design and response surface method (RSM). The RSM allows to solve multivariable equations and to estimate simultaneously the relative importance of several contributing parameters even in the presence of complex interaction. Airlift photoreactor imposed a synergistic effect combining good mixing intensity merit with high ozone transfer rate. Mixing in the airlift photoreactor enhanced the UV light usage efficiency and its availability. Complete degradation of trifluralin was achieved under optimum conditions of $\mathrm{pH} 9$ and superficial gas velocity $0.15 \mathrm{~cm} / \mathrm{s}$ after $60 \mathrm{~min}$ of reaction time. Under these conditions, degradation of trifluralin was performed in a bubble column photoreactor of similar volume and a lower efficiency was observed.
\end{abstract}

Keywords Advanced oxidation process · Airlift photoreactor - Ozone - Response surface method . Trifluralin · Ultraviolet irradiation

J. Behin

Behin@razi.ac.ir

1 Department of Chemical Engineering, Faculty of Engineering, Razi University, Baghe Abrisham, Kermanshah, Iran

\section{Introduction}

Rain and surface water runoff can transport pesticides from agricultural fields through the soil into underground reservoirs, rivers and lakes and reach drinking water supplies (Sasaki et al. 1991; Moza et al. 1998). In recent years, pesticide pollution of surface waters has increased substantially (Kaushik et al. 2010; Navarro et al. 2010). They reach ecosystems by direct application, aerial spraying, spray drift, atmospheric fallout, soil erosion and runoff from agricultural areas, discharge of industrial and domestic sewage, leaching, careless disposal of empty containers and equipment washing (Mattice et al. 2010; Luo et al. 2014).

Trifluralin, 2,6-dinitro- $N, N$-dipropyl-4-(trifluoromethyl) aniline, is one of the most common pesticides used to control pests and weeds in a wide variety of agricultural crops since 1960 (Constantin and Owens 1982). It generally ranks in the top ten agricultural pesticides according to annual sales and usage (Sipyagin et al. 2004). It is toxic to aquatic organisms, and the US Environmental Protection Agency has classified it into group C of possible human carcinogens (Greene 2005), as it is an endocrine disruptor (Rawlings et al. 1998). Trifluralin has mostly appeared in surface and runoff water $(0.001-0.08 \mathrm{ppm})$ as reported by several authors (Wilson et al.1996; Alegria and Shaw 1999; Moore et al. 2007; LeBlanc and Kuivila 2008).

The negative impact created by pesticide pollution on the environment has attracted our attention to the use of advanced oxidation processes (AOPs) in water treatments involving highly reactive hydroxyl radicals, $\mathrm{OH}$. (Parsons 2004; Ikehata and Gamal El-Din 2005a, b; Catalkaya and Kargi 2009; Chelme-Ayala et al. 2010; Asgari et al. 2014; Behin et al. 2015; Ribeiro et al. 2015). The hydroxyl 
radicals are generated via oxidizing agents such as $\mathrm{H}_{2} \mathrm{O}_{2}$, $\mathrm{O}_{3}$, ultraviolet irradiation (UV), or by combinations of oxidants with homogeneous or heterogeneous catalysts and recently ultrasound irradiations (US) (Gogate and Pandit 2004; Sanches et al. 2010; Mohajerani et al. 2012). Trifluralin degradation has not been studied widely; however, it is highly used in the world (Sipyagin et al. 2004; Ormad et al. 2008). Kearney et al. (1987) investigated the degradation of trifluralin $(10-100 \mathrm{ppm})$ by $\mathrm{O}_{3} /$ UV and more than $90 \%$ removal was obtained after $1 \mathrm{~h}$. Chelme-Ayala et al. (2011) studied the degradation of trifluralin $(3 \mu \mathrm{M})$ by $\mathrm{O}_{3}$ (aqueous saturated solution) and $\mathrm{O}_{3} / \mathrm{H}_{2} \mathrm{O}_{2}$. The highest degradation of $67 \%$ was observed at $\mathrm{pH} 9$ by $\mathrm{O}_{3} / \mathrm{H}_{2} \mathrm{O}_{2}$, whereas the corresponding value was lower than $50 \%$ in $\mathrm{O}_{3}$ alone. In another work, Chelme-Ayala et al. (2010) investigated the photodegradation of an aqueous solution of trifluralin by UV $(253.7 \mathrm{~nm})$ and $\mathrm{UV} / \mathrm{H}_{2} \mathrm{O}_{2}$ and $90 \%$ degradation was achieved with $\mathrm{UV} / \mathrm{H}_{2} \mathrm{O}_{2}$. The reaction kinetics and byproducts of photodegradation of trifluralin by UV-Vis light and simulated solar irradiation were investigated in detail by Tagle et al. (2005) and Dimou et al. (2004), respectively.

Based on the author's knowledge, no investigation that dealt with the use of $\mathrm{O}_{3} / \mathrm{UV} / \mathrm{H}_{2} \mathrm{O}_{2}$ for trifluralin degradation has been reported. To assure that each fluid element receives uniform UV radiation dose, choosing the proper mixing rate eliminates mass transfer limitations inside the reactor (Tabrizi and Mehrvar 2006). A reactor with the benefits of high efficiency, low energy input and easy construction to improve degradation efficiency is necessary. In this work, an airlift reactor (ALR) was applied where the gas injected in the riser permits fluid circulation throughout the downcomer.

\section{Materials and methods}

The experimental setup including the airlift photoreactor is schematically shown in Fig. 1. A Pyrex cylindrical reactor (10 cm in diameter and $45 \mathrm{~cm}$ in height) consisted of a draft tube with diameters of $4 \mathrm{~cm}$ and height of $35 \mathrm{~cm}$. The bubble column reactor geometry of similar volume was achieved by removing the draft tube from the airlift reactor. Ozone was produced from dried air using an ozone generator module $20 \mathrm{G} / \mathrm{H}$ (Arda, France). Its flow rate was measured with a rotameter before entering the reactor and its concentration was determined using an iodimetric method (Rakness et al. 1996). Ozone was injected into the riser and improved the circulation of liquid inside the reactor. The UV chamber was made up of four $\mathrm{UV}_{\mathrm{AB}}$ lamps (15 W, 280-400 nm, Narva, Germany). Continuous illumination was provided by UV lamps, fixed around the reactor with a lightened surface area of $0.141 \mathrm{~m}^{2}$. For each experimental run, the reactor was loaded with $3.5 \mathrm{~L}$ of an aqueous solution of trifluralin (initial concentration of $1 \mathrm{mg} / \mathrm{L})$. Trifluralin was obtained from Sigma-Aldrich (Canada) and was applied without further refinement. Then, $200 \mu \mathrm{L} \mathrm{H}_{2} \mathrm{O}_{2}$ (30\% w/w, Merck, Germany) was added to the solution. To adjust the $\mathrm{pH}$, a phosphate buffer solution was prepared using reagent-grade sodium phosphate monobasic, potassium phosphate, sodium hydroxide, and phosphoric acid. Trifluralin concentration was monitored by a high-performance liquid chromatography
Fig. 1 Schematic diagram of an airlift photoreactor

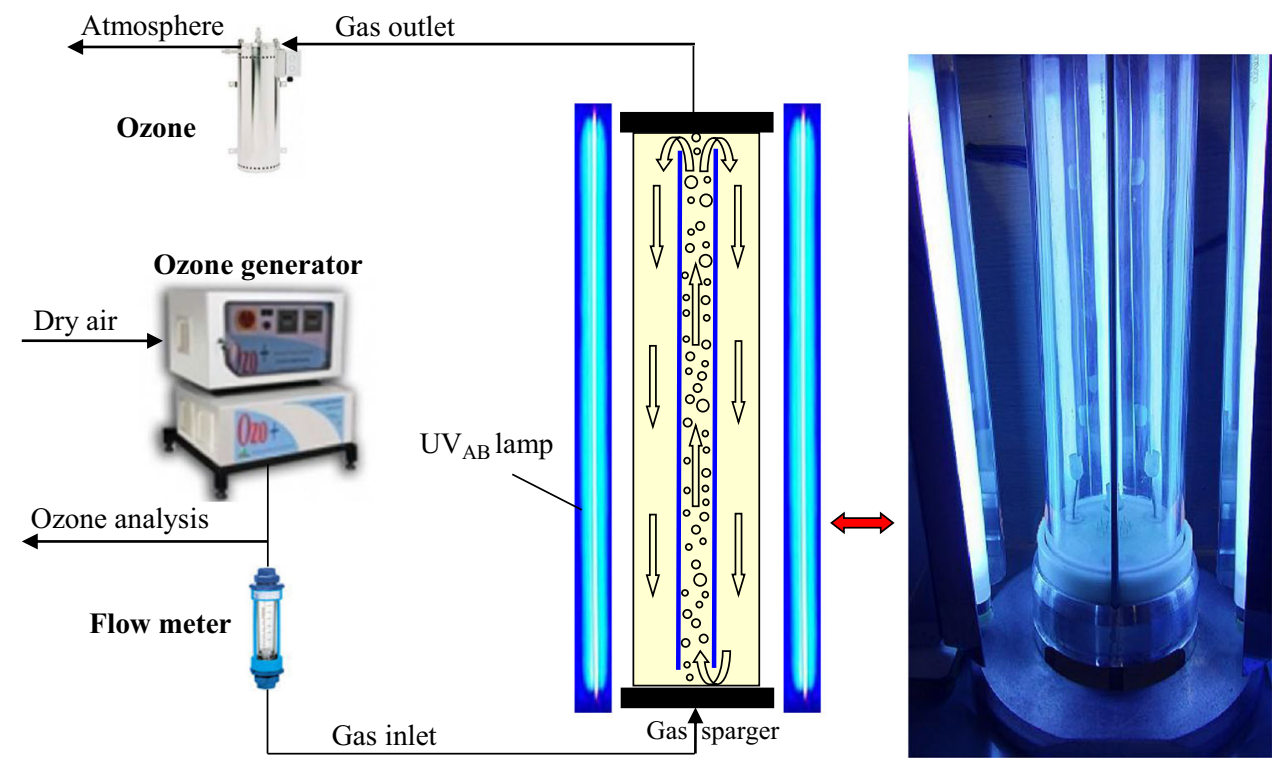


Table 1 High and low levels of experimental variables

\begin{tabular}{lllll}
\hline Independent variable & Unit & \multicolumn{3}{l}{ Levels and range } \\
\cline { 2 - 5 } & & -1 & 0 & 1 \\
\hline$A$ solution pH & - & 5 & 7 & 9 \\
$B$ superficial gas velocity & $\mathrm{cm} / \mathrm{s}$ & 0.05 & 0.10 & 0.15 \\
$C$ time & $\mathrm{min}$ & 20 & 40 & 60 \\
\hline
\end{tabular}

(HPLC) instrument (930D LC pump, UV730D detector, YoungLin instruments, Korea) equipped with a Tracer Excel 120 ODSA, $5 \mu \mathrm{m} 25 \times 0.46$ column. Trifluralin detection was carried out using an isocratic mode with acetonitrile and water $(75: 25 \% \mathrm{v} / \mathrm{v})$. All experiments were performed twice and the obtained standard deviation was always less than $5 \%$ of the reported value.

The degradation efficiency of trifluralin was determined using the following equation:

$\eta_{\mathrm{obs}}=\frac{C_{0}-C_{t}}{C_{0}}$,

where $\eta_{\mathrm{obs}}$ is the degradation efficiency $(\%), C_{0}$ is the initial concentration of trifluralin $(\mathrm{mg} / \mathrm{L})$ and $C_{t}$ is the concentration of trifluralin at time $t(\mathrm{mg} / \mathrm{L})$.

\section{Experimental design}

Response surface method (RSM) is an efficient statistical tool to optimize the operating conditions in multivariable systems by considering the interactions between variables. Using RSM, with a minimum number of experiments, an optimal response could be achieved (Ghafoori et al. 2012, 2015; Rajkumar and Muthukumar 2015).

The experiments were conducted by a central composite design (CCD) defined under RSM. Superficial gas velocity, $\mathrm{pH}$ and time were chosen as the independent variables in the $\mathrm{O}_{3} / \mathrm{UV} / \mathrm{H}_{2} \mathrm{O}_{2}$ process. The experimental design was conducted using Design Expert Software (ver. 7). High and low levels of the three independent variables are shown in Table 1.

\section{Results and discussion}

The $\mathrm{O}_{3} / \mathrm{UV} / \mathrm{H}_{2} \mathrm{O}_{2}$ process includes three components to generate $\mathrm{OH}$ - and oxidize the pollutant for pursuant reactions. The organic compound could be decomposed via two main oxidation mechanisms by $\mathrm{O}_{3}$. One is oxidation with molecular ozone and another pre-dominant indirect mechanism includes generation of $\mathrm{OH}$ - by $\mathrm{O}_{3}$ decomposition in aqueous solution. In the presence of $\mathrm{H}_{2} \mathrm{O}_{2}$, hydroxyl radicals are generated by the interaction between UV and $\mathrm{H}_{2} \mathrm{O}_{2}$. In this case, the free radical production process can be looked upon as $\mathrm{H}_{2} \mathrm{O}_{2}$ direct photolysis. Moreover, on $\mathrm{O}_{3}$ decomposition in an aqueous environment in the presence of $\mathrm{H}_{2} \mathrm{O}_{2}$, the free $\mathrm{OH}$. and the superoxide ion (Glaze et al. 1987) appear. The superoxide ion continues to further the $\mathrm{O}_{3}$ decomposition process. The rate of degradation of trifluralin was also enhanced by direct photolysis using UV. The AOPs with UV irradiation and $\mathrm{O}_{3}$ is initiated by the photolysis of ozone. The photo-decomposition of ozone produces $\mathrm{H}_{2} \mathrm{O}_{2}$ and, hence, generates more hydroxyl radicals (Kusic et al. 2006; Chelme-Ayala et al. 2010, 2011). A threevariable three-level central composite statistical experiment design was applied to investigate the effect of the independent variables on the response function and to find the optimal conditions for maximized degradation. The experimental conditions and the observed and predicted values for the degradation efficiency are presented in Table 2.

\section{Central composite model}

A relationship between the response and variables was attained by Design Expert Software and expressed by a reduced quadratic model. The quadratic model for predicting the degradation efficiency $\left(\eta_{\text {prd }}\right)$ in terms of the coded variables is as follows:

$$
\begin{aligned}
\eta_{\mathrm{prd}}= & 96.02+2.43 A+1.09 B+2.85 C-0.46 A B \\
& -1.31 A C-0.77 A^{2} .
\end{aligned}
$$

The negative coefficients for the model components indicate the unfavorable effects of $A B, A C$ and $A^{2}$ on the degradation efficiency, while the positive coefficients for $A, B$ and $C$ indicate favorable effects on the degradation efficiency.

The statistical importance of the model to predict the degradation of trifluralin was analyzed using the analysis of variance (ANOVA). Table 3 presents the statistical characteristics of the selected significant model's terms to characterize the trifluralin degradation efficiency as a function of the variables examined. From the analysis data, $A, B, C, A C, A B$ and $A^{2}$ are significant terms and other model's terms are not significant due to the $p$ value higher than 0.05 . The most to least significant reaction variables are presented as: 
Direct effect of time (2.85)

$>\quad$ Direct effect of $\mathrm{pH}(2.43)$

$>$ Interaction between the $\mathrm{pH}$ and time (-1.31)

$>\quad$ Direct effect of superficial gas velocity (1.09)

$>$ Second order effect of $\mathrm{pH}(-0.77)$

$>$ Interaction between the $\mathrm{pH}$ and superficial gas velocity $(-0.46)$

Table 2 Coded design matrix along with experimental and predicted value response

\begin{tabular}{|c|c|c|c|c|c|}
\hline \multirow[t]{3}{*}{$\begin{array}{l}\text { Run } \\
\text { no. }\end{array}$} & \multicolumn{3}{|l|}{ Factors } & \multicolumn{2}{|c|}{$\begin{array}{l}\text { Degradation } \\
\text { efficiency }(\%)\end{array}$} \\
\hline & $\begin{array}{l}\text { Solution } \\
\mathrm{pH} \\
A\end{array}$ & $\begin{array}{l}\text { Superficial gas } \\
\text { velocity }(\mathrm{cm} / \mathrm{s})\end{array}$ & $\begin{array}{l}\text { Time } \\
(\min )\end{array}$ & Observed & Predicted \\
\hline & & & & $\eta_{\mathrm{obs}}$ & $\eta_{\text {prd }}$ \\
\hline 1 & 1 & 1 & 1 & 99.60 & 99.84 \\
\hline 2 & -1 & 0 & 0 & 93.00 & 92.82 \\
\hline 3 & 0 & 0 & 0 & 96.00 & 96.02 \\
\hline 4 & 0 & 0 & 0 & 95.80 & 96.02 \\
\hline 5 & -1 & 1 & 1 & 98.40 & 98.53 \\
\hline 6 & 0 & 1 & 0 & 97.20 & 97.11 \\
\hline 7 & 0 & 0 & 0 & 96.50 & 96.02 \\
\hline 8 & 0 & 0 & 0 & 96.20 & 96.02 \\
\hline 9 & -1 & -1 & -1 & 86.90 & 87.10 \\
\hline 10 & -1 & 1 & -1 & 90.20 & 90.21 \\
\hline 11 & 1 & 1 & -1 & 96.90 & 96.77 \\
\hline 12 & 0 & 0 & 0 & 95.70 & 96.02 \\
\hline 13 & -1 & -1 & 1 & 95.60 & 95.43 \\
\hline 14 & 0 & 0 & 0 & 96.20 & 96.02 \\
\hline 15 & 0 & 0 & -1 & 93.30 & 93.17 \\
\hline 16 & 0 & 0 & 1 & 98.50 & 98.87 \\
\hline 17 & 1 & -1 & 1 & 98.90 & 98.59 \\
\hline 18 & 1 & -1 & -1 & 95.20 & 95.51 \\
\hline 19 & 0 & -1 & 0 & 94.80 & 94.93 \\
\hline 20 & 1 & 0 & 0 & 97.80 & 97.68 \\
\hline
\end{tabular}

The significance of each coefficient and the interaction strength between each independent variable was determined by $F$ value and $p$ value (Table 3 ).

A small probability value $(p<0.05)$ shows that the model was very significant. High values of the determination coefficient $\left(R^{2}\right)$ confirmed that the model fitted well to the experimental data. Moreover, adequate precision larger than 4 (76.37 in this case) indicates that the model could be appropriate for describing the present trifluralin degradation process.

An extent of the range in the predicted response toward its associated error is adequate precision.
Table 3 ANOVA for prediction of degradation efficiency by the reduced quadratic model

\begin{tabular}{|c|c|c|c|c|c|}
\hline \multirow[t]{2}{*}{ Parameters } & \multicolumn{5}{|c|}{ Statistics } \\
\hline & $\begin{array}{l}\text { Sum of } \\
\text { squares }\end{array}$ & $\begin{array}{l}\text { Degree of } \\
\text { freedom }\end{array}$ & $\begin{array}{l}\text { Mean } \\
\text { square }\end{array}$ & $F$ value & $p$ value \\
\hline Model & 170.61 & 6 & 28.44 & 357.68 & $<0.0001$ \\
\hline $\mathrm{A}: \mathrm{pH}$ & 59.05 & 1 & 59.05 & 742.75 & $<0.0001$ \\
\hline $\begin{array}{l}\text { B: Superficial } \\
\text { gas velocity }\end{array}$ & 11.88 & 1 & 11.88 & 149.45 & $<0.0001$ \\
\hline C: time & 81.22 & 1 & 81.22 & 1021.70 & $<0.0001$ \\
\hline$A B$ & 1.71 & 1 & 1.71 & 21.53 & 0.0005 \\
\hline$A C$ & 13.78 & 1 & 13.78 & 173.35 & $<0.0001$ \\
\hline$A^{2}$ & 2.96 & 1 & 2.96 & 37.29 & $<0.0001$ \\
\hline Residuals & 1.03 & 13 & 0.079 & & \\
\hline Pure error & 0.43 & 5 & 0.087 & & \\
\hline $\begin{array}{l}\text { Total } \\
R^{2}: 0.9940\end{array}$ & 171.65 & 19 & & & \\
\hline $\begin{array}{c}\text { Adjusted } R^{2} \text { : } \\
0.9912\end{array}$ & & & & & \\
\hline $\begin{array}{l}\text { Adequate } \\
\text { precision: } \\
76.37\end{array}$ & & & & & \\
\hline
\end{tabular}

The main diagnostic plots (Fig. 2) were applied to evaluate the residual analysis (difference between the observed and the predicted response value) of the response surface design and guaranty that the statistical assumptions fit the analysis data. It could be deduced that the predictions of the experimental data with the developed quadratic model for the degradation efficiency is exactly satisfactory. The results illustrated in Fig. 2 supply the general influence of a normal distribution of underlying errors, since the residuals lie along the line; therefore, the model is an acceptable fit with no apparent problem in normality and response transformation. Based on these plots, residuals plot appear to be scattered at random; thus, the model proposed is appropriate for data and the constant variance assumption is confirmed.

The 3D response surface and 2D contours based on the quadratic model were plotted, as shown in Fig. 3. These plots represent the variation of the response with two 

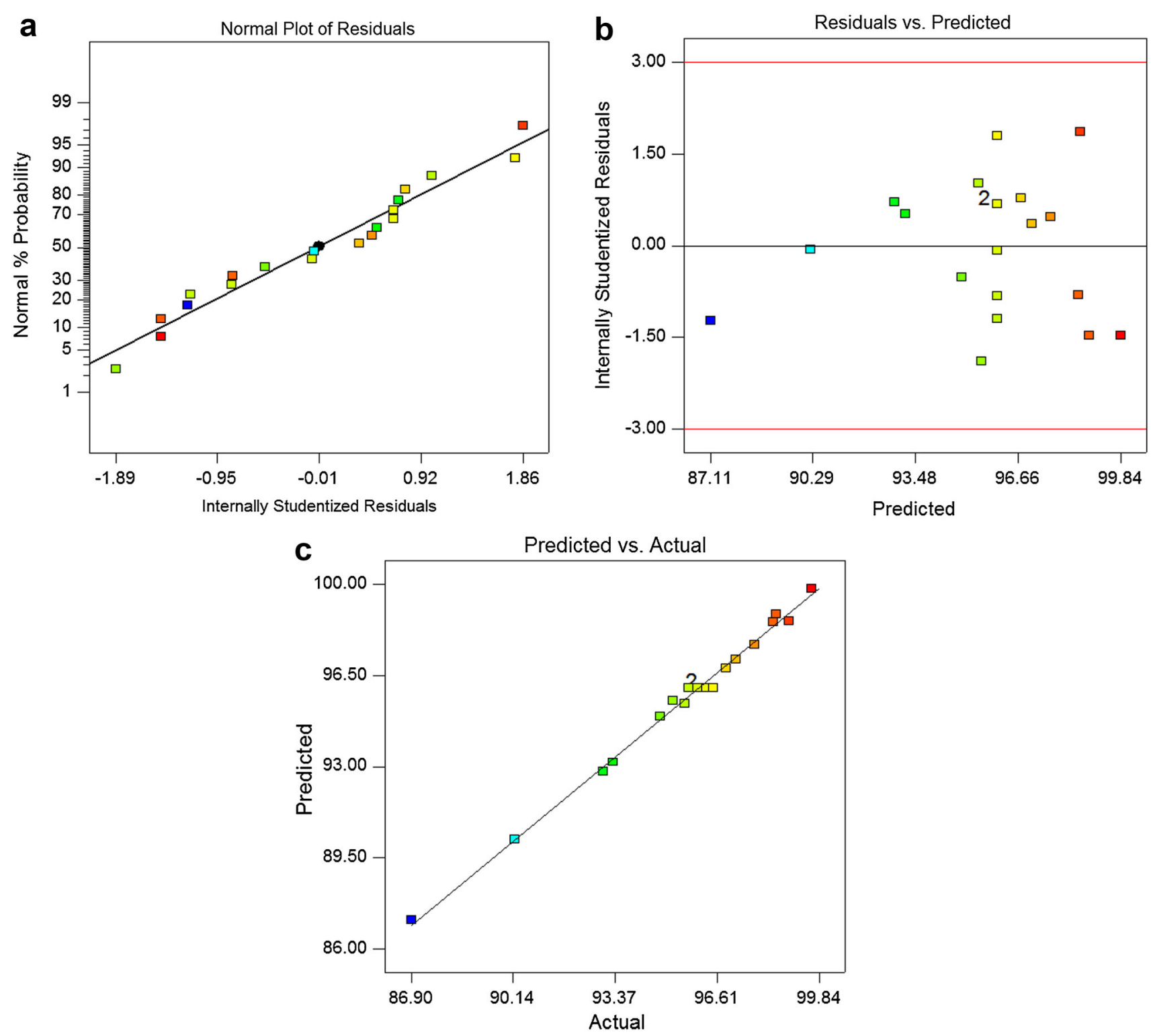

Fig. 2 a Normal probability plot of residual for degradation of trifluralin, b plot of residual versus predicted and $\mathbf{c}$ predicted versus actual value response for degradation efficiency

variables, keeping all the other variable fixed. The nonlinear nature of all 3D response surfaces shows considerable interactions between independent parameters and the degradation efficiency as a response function. The plots are nearly symmetrical in shape with circular contours. The clear peak in the response surfaces indicates that the optimum conditions were located in the experimental design region. The response surface plots indicate the optimum values for the maximum degradation efficiency, where $\mathrm{pH}$ is 9 , superficial gas velocity $0.15 \mathrm{~cm} / \mathrm{s}$ and time $60 \mathrm{~min}$. At these optimum values, the predicted and observed degradation efficiency was 100 and $99.6 \%$, respectively. Moving away from these points shows reduction in degradation efficiencies, suggesting that either decrease or increase in any of the examined variables leads to decrease in the response.

Figure 3a demonstrates the effect of reaction time and $\mathrm{pH}$ on the degradation efficiency at constant superficial gas velocity of $0.1 \mathrm{~cm} / \mathrm{s}$. Figure $3 \mathrm{~b}$ shows the effect of reaction time and superficial gas velocity on the degradation efficiency at a constant $\mathrm{pH}$ of 7 . The degradation efficiency increased sharply as the reaction time increased from 20 to $60 \mathrm{~min}$. In fact, with increasing reaction time, a significant effect of combined reactions among $\mathrm{O}_{3}, \mathrm{H}_{2} \mathrm{O}_{2}$ and $\mathrm{UV}$ was obtained, resulting in the production of more hydroxyl radicals. Figure $3 \mathrm{c}$ illustrates the effect of superficial gas velocity $(\mathrm{Ug})$ and $\mathrm{pH}$ on the degradation efficiency at constant reaction time of $40 \mathrm{~min}$. Increase in the $\mathrm{pH}$ of the 
Fig. 3 Interaction effects of different variables on the degradation efficiency using 3D response surface and $2 \mathrm{D}$ contour plots, a $\mathrm{pH}$ and time, b $\mathrm{Ug}$ and time, $\mathbf{c} \mathrm{pH}$ and $\mathrm{Ug}$
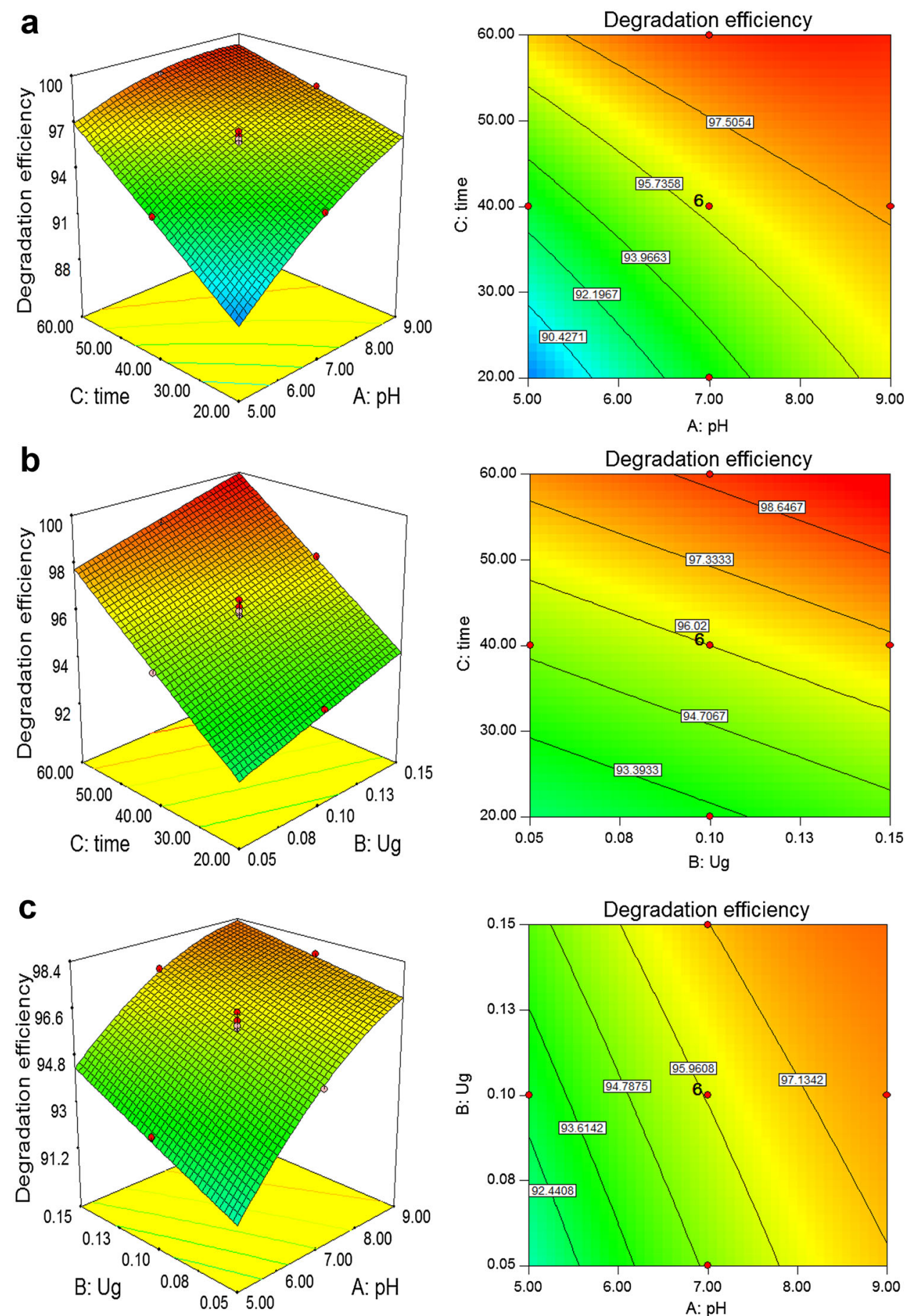

solution (from 5 to 9) increases the degradation efficiency for any reaction time. The $\mathrm{pH}$ of a solution plays an important role in the photo-oxidation process which depends on the nature of the contaminants. At higher $\mathrm{pH}$, the deprotonated pesticide species have superior reactivity with $\mathrm{O}_{3}$ than protonated species. In addition, the high levels of $\mathrm{OH}$. at $\mathrm{pH} 9$ could contribute to the enhancement of the pesticide oxidation at this $\mathrm{pH}$ (Chelme-Ayala et al.
2010, 2011). On increasing the superficial gas velocity from 0.05 to $0.15 \mathrm{~cm} / \mathrm{s}$, the degradation efficiency also increases. Higher gas flow rate supplies higher mixing efficiency and liquid circulation. Higher liquid circulation leads to greater degradation rate and mass transfer coefficient (Mohajerani et al. 2012). The decrease in the degradation time with increasing gas velocity is ascribed to the increment of the rate of mass transfer of $\mathrm{O}_{3}$ from gas 
bubbles to the liquid phase as a consequence of eddies produced in the wake of the ascending bubbles, lessening the diffusion layer thickness which surrounds the bubbles and enhancing the gas holdup. The enhancement in gas holdup increases the liquid-gas interfacial area with a resultant increase in the rate of mass transfer of $\mathrm{O}_{3}$ from the gas bubbles to the solution (Kuo 1982; Konsowa 2003).

\section{Effectiveness of different AOPs}

To study the synergistic effect under optimum conditions, the degradation efficiency of trifluralin was measured in six different combinations including $\mathrm{O}_{3}, \quad \mathrm{UV}, \mathrm{O}_{3} / \mathrm{UV}$, $\mathrm{O}_{3} / \mathrm{H}_{2} \mathrm{O}_{2}$, UV/ $\mathrm{H}_{2} \mathrm{O}_{2}$ and $\mathrm{O}_{3} / \mathrm{UV} / \mathrm{H}_{2} \mathrm{O}_{2}$ (Fig. 4). The effectiveness of the processes was compared based on the degradation efficiency. The $\mathrm{pH}$ and superficial gas velocity were kept constant at an optimum value of 9 and $0.15 \mathrm{~cm} / \mathrm{s}$, respectively. The degradation efficiency was found to be $68,82,84,91,98$ and $99.6 \%$ in the 60 min treatment period for $\mathrm{O}_{3}, \mathrm{O}_{3} / \mathrm{H}_{2} \mathrm{O}_{2}, \mathrm{UV}, \mathrm{O}_{3} / \mathrm{UV}, \mathrm{UV} / \mathrm{H}_{2} \mathrm{O}_{2}$ and $\mathrm{O}_{3} / \mathrm{UV} / \mathrm{H}_{2} \mathrm{O}_{2}$, respectively.

According to applied different treatments on trifluralin, the decreasing order of removal efficiency was observed as follows:

$\mathrm{UV} / \mathrm{H}_{2} \mathrm{O}_{2}>\mathrm{O}_{3} / \mathrm{UV}>\mathrm{UV}>\mathrm{O}_{3} / \mathrm{H}_{2} \mathrm{O}_{2}>\mathrm{O}_{3}$,

which is in agreement with literature (Kearney et al. 1987; Chelme-Ayala et al. 2010, 2011). However, all the $\mathrm{O}_{3} / \mathrm{UV}, \mathrm{UV} / \mathrm{H}_{2} \mathrm{O}_{2}$ and $\mathrm{O}_{3} / \mathrm{UV} / \mathrm{H}_{2} \mathrm{O}_{2}$ processes were capable of oxidizing aqueous trifluralin solution faster than ozone on its own, indicating a photochemical increment oxidation effect. This is fundamentally due to the photolysis of $\mathrm{O}_{3}$, the increased mass transfer of $\mathrm{O}_{3}$ and the production of hydroxyl radicals that react quickly with the organic pesticide in the aqueous solution (Lucasa et al. 2010).

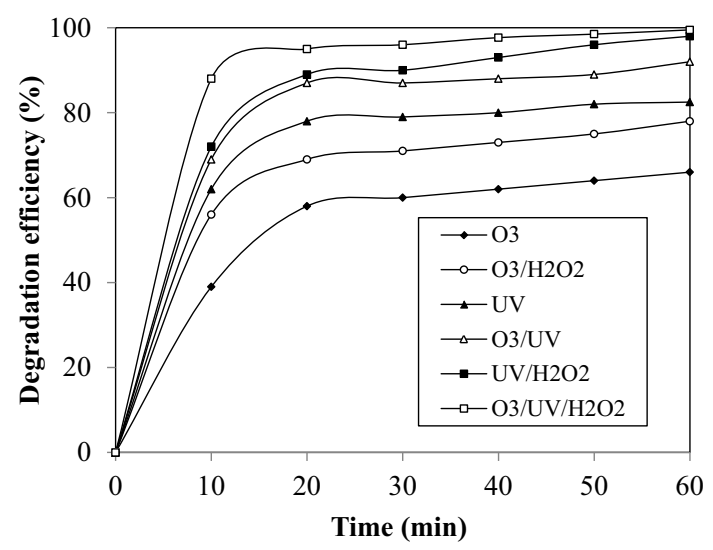

Fig. 4 Effect of $\mathrm{O}_{3}, \mathrm{UV}$ and $\mathrm{H}_{2} \mathrm{O}_{2}$ combinations on the degradation efficiency of trifluralin in the airlift photoreactor under optimum conditions $(\mathrm{pH} \mathrm{9,} \mathrm{Ug}=0.15 \mathrm{~cm} / \mathrm{s}$ )

\section{Cost evaluation of the $\mathrm{O}_{3} / \mathrm{UV} / \mathrm{H}_{2} \mathrm{O}_{2}$ process}

Today, the estimation of the treatment costs is one of the most important aspects. The overall costs are represented with the sum of the operating costs, the capital costs and maintenance. For a system, these costs forcefully depend on the configuration of the reactor and the flow rate of the effluent and also the nature of the effluent (Andreozzi et al. 1999; Esplugas et al. 2002). Some effort have been done for the estimation of the operating costs and to develop a procedure for the assessment of the electrical energy consumptions of UV lamps (Bolton and Cater 1994; Bolton et al. 1996; Andreozzi et al. 1999). According to this procedure, after fixing a reference level of degradation of a specified pollutant $(90 \%)$, a pseudo-first-order kinetic constant is evaluated. For a fixed volume of wastewater (i.e., $10^{3} \mathrm{~L}$ ), the energy needed for attaining the chosen level of abatement can be therefore obtained through the following relation:

$E=k \times \frac{\ln 10}{60} \times \frac{1000 P}{V_{0}}$,

where $P$ is the lamp power $(\mathrm{kW}) ; k$ is the pseudo-first-order constant $\left(\mathrm{min}^{-1}\right) ; V_{0}$ is the volume of the tested solution; and $E$ is the energy in $\mathrm{kWh}$ needed for achieving $90 \%$ removal of pollutants in $1000 \mathrm{~L}$ of treated wastewater.

In this work, continuous illumination was provided by four UV lamps, installed around the reactor to obtain a suitable distribution of light along the surface area of the reactor. Therefore, an average energy $(E)$ of $0.53 \mathrm{kWh}$ was calculated. Values of $E$ less than 2.5 are considered suitable for practical applications (Bolton and Cater 1994; Andreozzi et al. 1999). However, it is possible to reduce the UV lamp to two and have sufficient amount of light irradiation.

\section{Bubble column photoreactor}

To study the effect of hydrodynamics and reactor geometry on degradation efficiency, an experimental run was performed in a bubble column reactor (BCR) with the similar working volume of the airlift reactor (ALR). The BCR geometry was easily achieved by removing the draft tube of ALR. The degradation experiment was conducted in BCR under the optimum conditions obtained in ALR $(\mathrm{pH}$ 9, $\mathrm{Ug} 0.15 \mathrm{~cm} / \mathrm{s}$, time $60 \mathrm{~min}$ ) and a similar trend was observed. However, the degradation efficiency reached $98 \%$ in BCR, which was less than that obtained in ALR. This behavior might be due to better mixing conditions in the airlift photoreactor. To verify this reason, the residence time distribution (RTD) of the liquid phase was determined experimentally using the classical tracer response method. A specific amount of inert tracer $(10 \mathrm{ml}$ of a saturated $\mathrm{NaCl}$ 


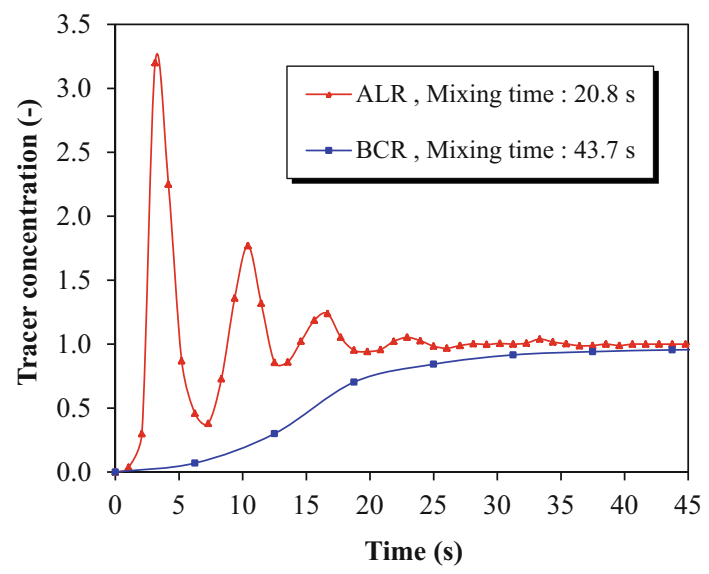

Fig. 5 Residence time distribution of airlift (ALR) and bubble column $(\mathrm{BCR})$ reactors $(\mathrm{Ug}=0.15 \mathrm{~cm} / \mathrm{s})$

solution) was injected within the reactor at a certain time $(t 0 \mathrm{~s})$ and its concentration measured as a function of time. Figure 5 illustrates the RTD of liquid in ALR and BCR, indicating higher mixing performance in ALR than BCR. Liquid mixing time is a significant qualitative index used mostly to represent the overall mixing property in the reactors, wherein a shorter mixing time represents a higher degree of mixing (Behin and Farhadian 2013, 2015). Mixing time is defined as the time needed to achieve a $5 \%$ deviation from complete homogeneity from the instance of tracer addition.

The superior performance of the airlift than bubble column photoreactor may be attributed to a well-defined flow pattern and better dispersion effects in the airlift that allows more effective light utilization efficiency. The generation of fluid circulation within the reactor increases the ozone mass transfer rate inside the liquid phase. During the degradation process, systematic mixing is important to bring all fluid elements to the vicinity of UV lamps and increase the photochemical degradation rate.

In the bubble column photoreactor, fluid elements and ozone bubbles nearer the light-receiving surface experienced a higher irradiation than bubbles elsewhere in the vessel. It seems that ultraviolet radiation decomposes $\mathrm{O}_{3}$ in the gas phase before it is transferred into the liquid phase and leads to a decrease in the efficiency of ozonation (Hayashi et al. 1993). Gaseous ozone absorbs ultraviolet radiation with wavelengths as long as $290-320 \mathrm{~nm}$ and is decomposed into $\mathrm{O}_{2}$ molecules. Ozone is much more reactive than oxygen and its equilibrium liquid concentration, and then the oxidation efficiency is decreased by this conversion:

$2 \mathrm{O}_{3}(\mathrm{~g})+h v \rightarrow 3 \mathrm{O}_{2}(\mathrm{~g})$.

As a consequence, the rate of the following reaction generating hydrogen peroxide is decreased:
$\mathrm{O}_{3}(\mathrm{aq})+\mathrm{H}_{2} \mathrm{O}+h v \rightarrow \mathrm{H}_{2} \mathrm{O}_{2}+\mathrm{O}_{2}$.

In the internal loop airlift photoreactor, the riser zone is not sufficiently illuminated by UV as the downcomer zone, where the following reaction is dominant:

$2 \mathrm{O}_{3}(\mathrm{aq})+\mathrm{H}_{2} \mathrm{O}_{2} \rightarrow 2 \mathrm{OH} \cdot+3 \mathrm{O}_{2}$.

Fluid elements move between the relatively low and highly illuminated zones intermittently and undergo a cyclic light effect ( $\mathrm{Li}$ and Yang 2013). The effect of circulatory flow and well-defined circulation pattern in the ALR allowed all the fluid elements to be exposed to high light intensity zone, and hence the effect of high light intensity was scattered evenly all over the medium (Merchuk et al. 1998; Monkonsit et al. 2011). The downcomer permits sufficient light penetration into the liquid depth to sustain reasonable photo-oxidation reaction rates as follows:

$\mathrm{H}_{2} \mathrm{O}_{2}+h v \rightarrow 2 \mathrm{OH}$.

In the bubble column, the cross section has a concentrated light region, and proper recirculation of fluid elements is not possible, since aeration only superimposes accidental movement with no net liquid motion. Whereas some fluid elements are subjected to high light intensity in the close vicinity of the illuminated column walls, those centrally positioned in the column are subjected to much lower light intensity leading to ineffective light utilization efficiency. Moreover, the gas bubbles are somewhat undesirable because they could hamper the passage of light to the center of the photoreactor, as the light penetration ability is blocked and dissipated with the swarm of bubbles. The ozonation in the riser of ALR was preferred to minimize the quantity of bubbles in the downcomer, which would reduce the efficiency due to light scattering (Roy 2015).

\section{Prospective $\mathrm{O}_{3} / \mathrm{UV} / \mathrm{H}_{2} \mathrm{O}_{2}$ process in an airlift photoreactor}

ALR is widely used in environmental and chemical industries because of its outstanding characteristic such as simple construction, low shear force, easy magnification and high efficiency (Xu et al. 2012). Moreover, the operating cost is relatively low, as the only power required is the electrical power to drive the airlift photoreactor $(60 \mathrm{~W}$ in the present case). The method of airlift photoreactor degradation has many advantages such as convenience, economy, safety and high efficiency; as a consequence, it has a good prospect in future applications. Airlift photoreactor is an advisable choice for treating organic wastewaters and it could be easily scaled up to an industrial one. More attention should be devoted in the future to identify scale-up parameters and the criteria for cost-effectiveness of the process. 


\section{Conclusions}

In this work, the treatment of an aqueous solution of trifluralin was studied by an advanced oxidation process including $\mathrm{O}_{3} / \mathrm{UV} / \mathrm{H}_{2} \mathrm{O}_{2}$ in an externally irradiated airlift photoreactor. The effects of $\mathrm{pH}$, superficial gas velocity and reaction time on the degradation efficiency were studied using RSM based on CCD. In the airlift photoreactor, due to the existence of a regular mixing pattern and exposure of the fluid elements to intermittent UV light which leads to enhance the efficiency of light utilization, the complete degradation efficiency of trifluralin was achieved. The reduced quadratic model developed indicated the significance of individual terms and some of the interaction terms. The model predictions and experimental data agreed well and the RSM could identify the most significant operating factors. Furthermore, this study examined the efficiency of trifluralin degradation in a bubble column photoreactor under optimal conditions. The results obtained in the laboratory-scale photoreactor demonstrate that the airlift is more efficient than the bubble column one in the treatment of aqueous pesticide solution.

Acknowledgments The authors gratefully acknowledge Gyah Corporation (Iran), especially M.Sc. M. Bamorowat and M.Sc. R. Bayat, for conducting HPLC analysis.

Open Access This article is distributed under the terms of the Creative Commons Attribution 4.0 International License (http:// creativecommons.org/licenses/by/4.0/), which permits unrestricted use, distribution, and reproduction in any medium, provided you give appropriate credit to the original author(s) and the source, provide a link to the Creative Commons license, and indicate if changes were made.

\section{References}

Alegria HA, Shaw TJ (1999) Rain deposition of pesticides in coastal waters of the South Atlantic Bight. Environ Sci Technol 33:850-856. doi:10.1021/es9806231

Andreozzi R, Caprio V, Insola A, Marotta R (1999) Advanced oxidation processes (AOP) for water purification and recovery. Catal Today 53:51-59. doi:10.1016/S0920-5861(99)00102-9

Asgari G, Samiee F, Ahmadian M, Poormohammadi A, solimanzadeh B (2014) Catalytic ozonation of pentachlorophenol in aqueous solutions using granular activated carbon. Appl Water Sci. doi:10.1007/s13201-014-0254-y

Behin J, Farhadian N (2013) Residence time distribution measurements in a two dimensional rectangular airlift reactor by digital image processing. Exp Therm Fluid Sci 51:244-250. doi:10. 1016/j.expthermflusci.2013.08.004

Behin J, Farhadian N (2015) Digital image processing technique to investigate the hydrodynamics of an airlift reactor with double downcomer. Chem Eng Technol 38:2207-2216. doi:10.1002/ ceat. 201500432

Behin J, Farhadian N, Ahmadi M, Parvizi M (2015) Ozone assisted electrocoagulation in a rectangular internal-loop airlift reactor: application to decolorization of acid dye. J Water Process Eng 8:171-178. doi:10.1016/j.jwpe.2015.10.003

Bolton JR, Cater SR (1994) Homogeneous photodegradation of pollutants in contaminated water. In: Helz GR, Zeep RG, Crosby DG (eds) An introduction, aquatic and surface photochemistry. Lewis, Boca Raton, pp 467-490

Bolton JR, Bircher KG, Tumas W, Tolman CA (1996) Figures of merit for the technical development and application of advanced oxidation processes. J Adv Oxid Technol 113:1-11

Catalkaya EC, Kargi F (2009) Degradation and mineralization of simazine in aqueous solution by ozone/hydrogen peroxide advanced oxidation. J Environ Eng 135:1357-1364. doi:10. 1061/(ASCE)EE.1943-7870.0000112

Chelme-Ayala P, Gamal El-Din M, Smith DW (2010) Degradation of bromoxynil and trifluralin in natural water by direct photolysis and UV plus $\mathrm{H}_{2} \mathrm{O}_{2}$ advanced oxidation process. Water Res 44:2221-2228. doi:10.1016/j.watres.2009.12.045

Chelme-Ayala P, Gamal El-Din M, Smith DW, Adams CD (2011) Oxidation kinetics of two pesticides in natural waters by ozonation and ozone combined with hydrogen peroxide. Water Res 45:2517-2526. doi:10.1016/j.watres.2011.02.007

Constantin MJ, Owens ET (1982) Introduction and perspectives of plant genetic and cytogenetic assays a report of the US environmental protection agency Gene-Tox program. Mutat Res/Rev Genet Toxicol 99:1-12. doi:10.1016/01651110(82)90027-6

Dimou AD, Vasilios AS, Triantafyllos AA (2004) Trifluralin photolysis in natural waters and under the presence of isolated organic matter and nitrate ions: kinetics and photoproduct analysis. J Photochem Photobiol A Chem 163:473-480. doi:10. 1016/j.jphotochem.2004.02.001

Esplugas S, Gimenez J, Contreras S, Pascual E, Rodriguez M (2002) Comparison of different advanced oxidation processes for phenol degradation. Water Res 36:1034-1042. doi:10.1016/ S0043-1354(01)00301-3

Ghafoori S, Mehrvar M, Chen P (2012) Free-radical-induced degradation of aqueous polyethylene oxide by $\mathrm{UV} / \mathrm{H}_{2} \mathrm{O}_{2}$ : experimental design, reaction mechanisms, and kinetic modeling. Ind Eng Chem Res 51:14980-14993. doi:10.1021/ ie 3005995

Ghafoori S, Mowla A, Jahani R, Mehrvar M, Chan PK (2015) Sonophotolytic degradation of synthetic pharmaceutical wastewater: statistical experimental design and modeling. J Environ Manag 150:128-137. doi:10.1016/j.jenvman.2014.11.011

Glaze WH, Kang JW, Chapin DH (1987) The chemistry of water treatment processes involving ozone, hydrogen peroxide and ultraviolet radiation. Ozone Sci Eng J Int Ozone Assoc 9:335-352. doi:10.1080/01919518708552148

Gogate PR, Pandit AB (2004) A review of imperative technologies for wastewater treatment. I. Oxidation technologies at ambient conditions. Adv Environ Res 8:501-551. doi:10.1016/S10930191(03)00032-7

Greene SA (2005) Sittig's handbook of pesticides and agricultural chemicals. William Andrew, Norwich

Hayashi J, Ikeda J, Kusakabe K, Morooka S (1993) Decomposition rate of volatile organochlorines by ozone and utilization efficiency of ozone with ultraviolet radiation in a bubble-column contactor. Water Res 27:1091-1097. doi:10.1016/00431354(93)90074-R

Ikehata K, Gamal El-Din M (2005a) Aqueous pesticide degradation by ozonation and ozone-based advanced oxidation processes: a review (part I). Ozone Sci Eng 27:83-114. doi:10.1080/ 01919510590945732

Ikehata K, Gamal El-Din M (2005b) Aqueous pesticide degradation by ozonation and ozone-based advanced oxidation processes: a

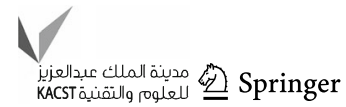


review (part II). Ozone Sci Eng 27:173-202. doi:10.1080/ 01919510590945732

Kaushik A, Sharma HR, Jain S, Dawra J, Kaushik CP (2010) Pesticide pollution of river Ghaggar in Haryana, India. Environ Monit Assess 160:61-69. doi:10.1007/s10661-008-0657-z

Kearney PC, Muldoon MT, Somich CJ (1987) UV-ozonation of eleven major pesticides as a waste disposal pretreatment. Chemosphere 16:2321-2330. doi:10.1016/00456535(87)90289-X

Konsowa AH (2003) Decolorization of wastewater containing direct dye by ozonation in a batch bubble column reactor. Desalination 158:233-240. doi:10.1016/s0011-9164(03)00458-2

Kuo CH (1982) Mass transfer in ozone absorption. Environ Progress 1:189-195. doi:10.1002/ep.670010312

Kusic H, Koprivanac N, Bozic AL (2006) Minimization of organic pollutant content in aqueous solution by means of AOPs: UVand ozone-based technologies. Chem Eng J 123:127-137. doi:10.1016/j.cej.2006.07.011

LeBlanc LA, Kuivila KM (2008) Occurrence, distribution and transport of pesticides into the Salton Sea Basin, California, 2001-2002, The Salton Sea Centennial Symposium. Dev Hydrobiol 201:151-172. doi:10.1007/s10750-008-9316-1

Li X, Yang N (2013) Modeling the light distribution in airlift photobioreactors under simultaneous external and internal illumination using the two-flux model. Chem Eng Sci 88:16-22. doi:10.1016/j.ces.2012.11.015

Lucasa MS, Peres JA, Puma GL (2010) Treatment of winery wastewater by ozone-based advanced oxidation processes $\left(\mathrm{O}_{3}\right.$, $\mathrm{O}_{3} / \mathrm{UV}$ and $\mathrm{O}_{3} / \mathrm{UV} / \mathrm{H}_{2} \mathrm{O}_{2}$ ) in a pilot-scale bubble column reactor and process economics. Sep Purif Tech 72:235-241. doi:10. 1016/j.seppur.2010.01.016

Luo Y, Guo W, Ngo HH, Nghiem LD, Hai FI, Zhang J, Liang S, Wang XC (2014) A review on the occurrence of micropollutants in the aquatic environment and their fate and removal during wastewater treatment. Sci Total Environ 473:619-641. doi:10. 1016/j.scitotenv.2013.12.065

Mattice JD, Skulman BW, Norman RJ, Gbur EE (2010) Analysis of river water for rice pesticides in eastern Arkansas from 2002 to 2008. J Soil Water Conserv 65:130-140. doi:10.2489/jswc.65.2.130

Merchuk JC, Ronen M, Geris S, Arad S (1998) Light/dark cycles in the growth of the red microalga Porphylidium sp. Biotechnol Bioeng 59:705-713. doi:10.1002/(sici)1097-0290(19980920)59: 6<705:aid-bit7>3.0.co;2-j

Mohajerani M, Mehrvar M, Ein-Mozaffari F (2012) Using an external-loop airlift sonophotoreactor to enhance the biodegradability of aqueous sulfadiazine solution. Sep Purif Tech 90:173-181. doi:10.1016/j.seppur.2012.02.025

Monkonsit S, Powtongsook S, Pavasant P (2011) Comparison between airlift photobioreactor and bubble column for skeletonema costatum cultivation. Eng J 15:53-64. doi:10.4186/ej. 2011.15.4.53

Moore MT, Lizotte RE Jr, Knight SS, Smith S Jr, Cooper CM (2007) Assessment of pesticide contamination in three Mississippi Delta oxbow lakes using Hyalella azteca. Chemosphere 67:2184-2191. doi:10.1016/j.chemosphere.2006.12.026

Moza PN, Hustert K, Feicht E, Kettrup A (1998) Photolysis of imidacloprid in aqueous solution. Chemosphere 36:497-502. doi:10.1016/S0045-6535(97)00359-7

Navarro A, Tauler R, Lacorte S, Barcelo D (2010) Occurrence and transport of pesticides and alkylphenols in water samples along the Ebro river basin. J Hydrol 383:18-29. doi:10.1016/j.jhydrol. 2009.06.039

Ormad MP, Miguel N, Claver A, Matesanz JM, Ovelleiro JL (2008) Pesticides removal in the process of drinking water production. Chemosphere 71:97-106. doi:10.1016/j.chemosphere.2007.10. 006

Parsons S (2004) Advanced oxidation processes for water and wastewater treatment. IWA, London

Rajkumar K, Muthukumar M (2015) Response surface optimization of electro-oxidation process for the treatment of C.I. Reactive Yellow 186 dye: reaction pathways. Appl Water Sci. doi:10. 1007/s13201-015-0276-0

Rakness K, Gordon G, Langlais B, Masschelein W, Matsumoto N, Richard Y, Robson CM, Somiya I (1996) Guideline for measurement of ozone concentration in the process gas from an ozone generator. Ozone Sci Eng 18:209-229. doi:10.1080/ 01919519608547327

Rawlings NC, Cook SJ, Waldbillig D (1998) Effects of the pesticides carbofuran, chlorpyrifos, dimethoate, lindane, triallate, trifluralin, 2,4-D, and pentachlorophenol on the metabolic endocrine and reproductive endocrine system in ewes. J Toxicol Environ Health A 54:21-36. doi:10.1080/009841098159006

Ribeiro AR, Nunes OC, Pereira MFR, Silva AMT (2015) An overview on the advanced oxidation processes applied for the treatment of water pollutants defined in the recently launched Directive 2013/39/EU. Environ Int 75:33-51. doi:10.1016/j. envint.2014.10.027

Roy D (2015) Novel bioreactors for culturing marine organisms, a chapter of springer handbook of marine biotechnology. Springer, Berlin, pp 327-386

Sanches S, Barreto Crespo MT, Pereira VJ (2010) Drinking water treatment of priority pesticides using low pressure UV photolysis and advanced oxidation processes. Water Res 44:1809-1818. doi:10.1016/j.watres.2009.12.001

Sasaki K, Ishizaka T, Suzuki T, Takeda M, Uchiyama M (1991) Accumulation levels of organochlorine pesticides in human adipose tissue and blood. Bull Environ Contam Toxicol 46:662-669. doi:10.1007/BF01689949

Sipyagin AM, Enshov VS, Kashtanov SA, Bateman CP, Mullen BD, Ying-Teck Tan, Thrasher JS (2004) New 4-pentafluorosulfanyl and 4-perfluoroalkylthio derivatives of 1-chloro-2-nitro-and 1-chloro-2, 6-dinitrobenzenes. J Fluor Chem 125:1305-1316. doi:10.1016/j.jfluchem.2004.03.008

Tabrizi GB, Mehrvar M (2006) Pilot-plant study for the photochemical treatment of aqueous linear alkyl benzene sulfonate. Sep Purif Tech 49:115-121. doi:10.1016/j.seppur.2005.09.003

Tagle MG, Laura Salum M, Bujan EI, Arguello GA (2005) Time evolution and competing pathways in photodegradation of trifluralin and three of its major degradation products. Photochem Photobiol Sci 4:869-875. doi:10.1039/b511957j

Wilson C, Whitwell T, Riley MB (1996) Detection and dissipation of isoxaben and trifluralin in containerized plant nursery runoff water. Weed Sci 44:683-688. doi:10.13140/2.1.4764.2248

Xu H, Li M, Wang J (2012) Photocatalytic degradation of methylene blue using Nano-ZnO at air lift circulating reactor. Adv Mat Res 476-478:1910-1914. doi:10.4028/www.scientific.net/AMR.476478.1910 